\title{
Inner plasma structure of the low-latitude reconnection layer
}

\author{
Q.-H. Zhang, ${ }^{1}$ M. W. Dunlop, ${ }^{2,3}$ M. Lockwood, ${ }^{2,4}$ B. Lavraud, ${ }^{5}$ Y. V. Bogdanova, ${ }^{6}$
} H. Hasegawa, ${ }^{7}$ H.-G. Yang, ${ }^{1}$ R.-Y. Liu, ${ }^{1}$ H.-Q. Hu, ${ }^{1}$ B.-C. Zhang, ${ }^{1}$ Z.-Y. Pu, ${ }^{8}$ Z.-W. Yang, ${ }^{1}$ J. Wang, ${ }^{8}$ M. G. G. T. Taylor, ${ }^{9}$ J. Berchem, ${ }^{10}$ D. Constantinescu, ${ }^{11}$ M. Volwerk, ${ }^{12}$ H. Frey, ${ }^{13}$ A. N. Fazakerley, ${ }^{6}$ C. Shen, ${ }^{3}$ J.-K. Shi, ${ }^{3}$ D. Sibeck, ${ }^{14}$ P. Escoubet, ${ }^{9}$ and J. A. Wild ${ }^{15}$ Received 15 February 2012; revised 11 May 2012; accepted 18 June 2012; published 3 August 2012.

[1] We report a clear transition through a reconnection layer at the low-latitude magnetopause which shows a complete traversal across all reconnected field lines during northwestward interplanetary magnetic field (IMF) conditions. The associated plasma populations confirm details of the electron and ion mixing and the time history and acceleration through the current layer. This case has low magnetic shear with a strong guide field and the reconnection layer contains a single density depletion layer on the magnetosheath side which we suggest results from nearly field-aligned magnetosheath flows. Within the reconnection boundary layer, there are two plasma boundaries, close to the inferred separatrices on the magnetosphere and magnetosheath sides $\left(\mathrm{S}_{\mathrm{sp}}\right.$ and $\left.\mathrm{S}_{\mathrm{sh}}\right)$ and two boundaries associated with the Alfvén waves (or Rotational Discontinuities, $\mathrm{RD}_{\mathrm{sp}}$ and $\mathrm{RD}_{\mathrm{sh}}$ ). The data are consistent with these being launched from the reconnection site and the plasma distributions are well ordered and suggestive of the time elapsed since reconnection of the field lines observed. In each sub-layer between the boundaries the plasma distribution is different and is centered around the current sheet, responsible for magnetosheath acceleration. We show evidence for a velocity dispersion effect in the electron anisotropy that is consistent with the time elapsed since reconnection. In addition, new evidence is presented for the occurrence of partial reflection of magnetosheath electrons at the magnetopause current layer.

Citation: Zhang, Q.-H., et al. (2012), Inner plasma structure of the low-latitude reconnection layer, J. Geophys. Res., 117, A08205, doi:10.1029/2012JA017622.

\section{Introduction}

[2] Magnetic reconnection (MR) of the Earth's dayside magnetic field with the adjacent magnetosheath magnetic field is believed to control the transport of plasma and energy from the solar wind into the magnetospheric environment by generating "open" field lines that thread the magnetopause [see, e.g., Paschmann, 2008]. Boundary layers, found both inside and outside the magnetopause current sheet and containing

${ }^{1}$ SOA Key Laboratory for Polar Science, Polar Research Institute of China, Shanghai, China.

${ }^{2}$ Rutherford Appleton Laboratory, Chilton, UK.

${ }^{3}$ CSSAR, CAS, Beijing, China.

${ }^{4}$ Department of Meteorology, University of Reading, Reading, UK.

${ }^{5}$ Institut de Recherche en Astrophysique et Planétologie, Toulouse, France.

${ }^{6}$ Mullard Space Science Laboratory, University College London, Dorking, UK.

Corresponding author: Q.-H. Zhang, SOA Key Laboratory for Polar Science, Polar Research Institute of China, No. 451, Jinqiao Rd., Pudong, Shanghai, 200136, China. (zhangqinghe@pric.gov.cn)

(C)2012. American Geophysical Union. All Rights Reserved. 0148-0227/12/2012JA017622 a mixture of magnetosheath and magnetospheric plasmas [e.g., Eastman and Hones, 1979; Mitchell et al., 1987; Gosling et al., 1990; Fuselier et al., 1995; Hall et al., 1991; Retinò et al., 2005; Khotyaintsev et al., 2006; Dunlop et al., 2008; Zhang et al., 2008, 2010], are generally thought to result from magnetic reconnection at the dayside magnetopause and to lie on field lines that either are open [Lockwood and Moen, 1996; Fuselier et al., 1997; Lockwood et al., 2001], or recently were open and then have been reclosed

\footnotetext{
${ }^{7}$ Institute of Space and Astronautical Science, JAXA, Sagamihara, Japan.

${ }^{8}$ School of Earth and Space Sciences, Peking University, Beijing, China.

${ }^{9}$ ESTEC, ESA, Noordwijk, Netherlands.

${ }^{10}$ IGPP, UCLA, Los Angeles, California, USA.

${ }^{11}$ Institut für Geophysik und Meteorologie, TU-BS, Braunschweig, Germany.

${ }^{12}$ Space Research Institute, Austrian Academy of Sciences, Graz, Austria.

${ }^{3}$ Space Sciences Laboratory, University of California, Berkeley, California, USA.

${ }^{14}$ NASA GSFC, Greenbelt, Maryland, USA.

${ }^{15}$ Department of Physics, Lancaster University, Lancaster, UK.
} 
[Onsager et al., 2001; Phan et al., 2005; Lavraud et al., 2005, 2006; Bogdanova et al., 2005, 2008].

[3] During southward IMF, reconnection is commonly observed at the low-latitude magnetopause. Impulsive bursts of dayside reconnection, called flux transfer events (FTEs), can be a sizable contribution to the transfer of flux from the Earth's magnetosheath to the magnetosphere [see Lockwood et al., 1995]. Lockwood and Hapgood [1998] showed that an FTE is a transient thickening of the low-latitude boundary layer (LLBL) on newly opened field lines caused by a pulse of enhanced reconnection rate. During northward IMF, reconnection is often found to occur at the high-latitude magnetopause between the magnetosheath and lobe magnetic field lines in one hemisphere [Gosling et al., 1991; Kessel et al., 1996; Lavraud et al., 2002] or in both hemispheres [Cowley, 1983; Song and Russell, 1992; Onsager et al., 2001; Lavraud et al., 2005, 2006; Bogdanova et al. 2005, 2008], and reconnection at the low-latitude magnetopause is less efficient or absent [e.g., Lockwood and Moen, 1999]. Reconnection in one or both hemispheres can give boundary layers on, respectively, open or recently re-closed field lines and suggest differences to the behaviors of the magnetosheath boundary layer under northward or southward IMF conditions. Lockwood and Hapgood [1997] argued that the observed evolution of particle populations in the LLBL reveals the importance of time elapsed since reconnection and that LLBL is typically on open field lines for a magnetospheric FTE. On the other hand, Phan et al. [2005] argued that bidirectional electron population at magnetosheath energies (below 300-400 eV) with balanced fluxes at all energies in the parallel and antiparallel direction can be a signature of closed field lines. Bogdanova et al. [2008] and $H u$ et al. [2008] showed that such bi-directional electron populations with equal fluxes at all energies are indeed a good indication of the closed magnetic field line topology inside the cusp and LLBL. Bogdanova et al. [2005] also confirmed that almost isotropic electron and ion populations can be observed on reclosed field lines inside the cusp, depending on the time history since dual lobe reconnection. Fuselier et al. [1999] argue that the bidirectional electrons are a signature of open, rather than closed, field lines with the electrons mirroring at low altitudes. However, Bogdanova et al. [2008] showed that there is a difference in the bi-directional magnetosheath-like electron populations existing on the open or closed field lines of the LLBL inside the magnetopause. As emphasized by Onsager et al. [2001] and Lavraud et al. [2005, 2006], determination of whether field lines are closed or open may primarily be based on the observation of heated electrons outside the magnetopause, rather than inside as most other studies have focused on. Another feature of the northwardIMF magnetopause is the Plasma Depletion Layer (PDL) which is most prominent at the nose of the magnetosphere [Crooker et al., 1979; Paschmann et al., 1993; Bogdanova et al., 2008]. This is usually understood in terms of the pile up of magnetic flux tubes draped over the nose of the magnetosphere: the increase in magnetic pressure means that the plasma pressure, and hence concentration, is reduced [Oieroset et al., 2004]. The presence of low-latitude reconnection, however, is accepted to reduce or remove the PDL by limiting the magnetic flux build up [Anderson et al., 1997].
[4] In this study, we report one of the first, clear transitions through a low-latitude reconnection layer in the morning sector of the magnetopause, which shows a complete traversal across all reconnected field lines. The associated plasma populations confirms details of the electron and ion mixing, time history and acceleration through the current layer, which is consistent with an open LLBL despite the fact that both the IMF and the magnetosheath field were northward.

\section{Instrumentation}

[5] THEMIS, launched on February 17, 2007, consists of five identical satellites (called "probes") [Angelopoulos, 2008]. Each spacecraft carries a complement of thermal plasma instrumentation, measuring the full 3-D ion and electron distributions in the energy range $4 \mathrm{eV}-25 \mathrm{keV}$ [McFadden et al., 2008], and fluxgate magnetometers, which provide calibrated data to an accuracy of better than $0.1 n T$ [Auster et al., 2008]. The Digital Fields Board (DFB) of THEMIS performs the data acquisition and signal processing of the Electric Field Instrument (EFI) [Bonnell et al., 2008] and the Search Coil magnetometers (SCM) [Roux et al., 2008] measurements. Two spectral data sets are produced, the FilterBank (FBK) and the Fast Fourier Transform (FFT). The FBK data set has continuous time coverage but poor spectral resolution; it is calculated as the mean of the absolute value of the band-pass filtered signals from 6 spectra bands. For a detailed description of the DFB, as well as a complete list of the frequency bins and band widths of the FBK and FFT data sets, see Cully et al. [2008]. Neither the FBK nor the FFT data contain the full 3-D wavefields due to the limitation of the onboard storage availability. For example, in our event, which represents the normal measurement condition, the EFI FBK data are available only for one of the spin-plane sensors (E12). We use plasma data with a $3 \mathrm{~s}$ resolution from the Electro-Static Analyzer (ESA) instrument, the electric field spectrum data with a 4 s resolution from FBK data and temporally averaged magnetic field data at a time resolution of one vector every $0.25 \mathrm{~s}$ from the fluxgate magnetometers.

[6] During the first 7 months of the mission the probes traversed the flank and dayside magnetosphere in a stringof-pearls configuration in highly elliptical orbits with 14.7 $\mathrm{R}_{\mathrm{E}}$ apogee and $16^{\circ}$ inclination, coasting en-route to deployment onto their final orbits for their baseline science [Sibeck and Angelopoulos, 2008].

[7] During this interval, the ACE satellite, in a halo orbit around the L1 Lagrange point, monitored the upstream solar wind and IMF conditions. The ACE spacecraft was located at about $(232.1,34.0,-20.4) \mathrm{R}_{\mathrm{E}}$ in GSM coordinates around 08:32UT on 26 August 2007. Solar wind data with $64 \mathrm{~s}$ resolution from the Solar Wind Experiment [McComas et al., 1998] and IMF data with $16 \mathrm{~s}$ resolution from the Magnetometer instrument [Smith et al., 1998] onboard the ACE spacecraft are used in this study.

\section{Observations and Results}

\subsection{Upstream Solar Wind and IMF Conditions}

[8] Figure 1 presents an overview of the solar wind and IMF conditions measured by the ACE satellite on 26 August 


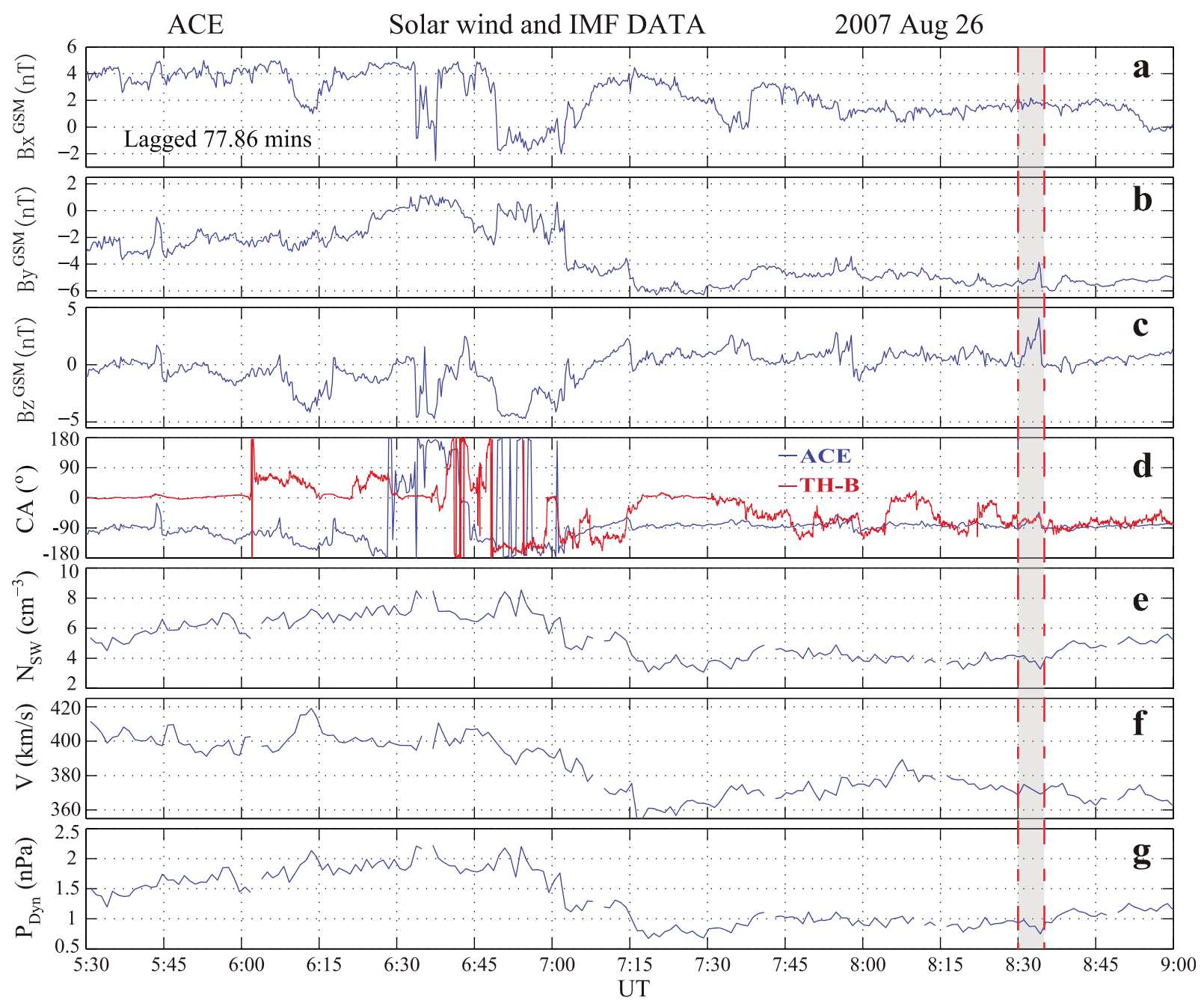

Figure 1. An overview of the solar wind and IMF conditions measured by the ACE satellite. Parameters shown are: the GSM IMF components (a) $B_{X}$, (b) $B_{Y}$, and (c) $B_{Z}$; (d) the IMF clock angle, CA (together with clock angle from THEMIS B); (e) the solar wind plasma number density, $\mathrm{N}_{\mathrm{sw}}$; (f) the solar wind speed, $\mathrm{V}$; and $(\mathrm{g})$ the solar wind dynamic pressure, $\mathrm{P}_{\mathrm{dyn}}$.

2007. Parameters shown are: the IMF components (in the GSM coordinate system), $B_{X}$ (Figure $\left.1 a\right), B_{Y}$ (Figure $\left.1 b\right), B_{Z}$ (Figure 1c); the IMF clock angle (Figure 1d); the solar wind plasma number density (Figure 1e); the solar wind speed (Figure 1f); and the solar wind dynamic pressure (Figure 1g). The data have all been lagged by 77.86 min which is the estimated propagation delay from the spacecraft to the magnetopause: this time delay is calculated from the best lagged fit to the magnetosheath data (particularly the IMF clock angle which is largely conserved on crossing the bow shock) observed by THEMIS B after about 0826 UT. During this interval, the IMF $\mathrm{B}_{\mathrm{Z}}$ component was mainly negative with some short positive excursions before 0709 UT and was mainly positive with some short negative excursions after 0709 UT, varying between -4.6 to $4.1 \mathrm{nT}$ (see Figure 1c), while the $\mathrm{B}_{\mathrm{Y}}$ component was dominated by negative values with some small positive values around 0635 and 0700 UT, varying between -6.0 and1.2 nT (see Figure 1b). The IMF clock angle (defined as positive for rotation from the $+Z$ direction toward $+Y$ ) mainly varied between -180 and $0^{\circ}$ with some positive excursions around 0635 and 0700 UT (see Figure 1d). The solar wind density increased from 4.5 to $8.5 \mathrm{~cm}^{-3}$ and then decreased to $3.0 \mathrm{~cm}^{-3}$ (see Figure $1 \mathrm{e}$ ), while the solar wind velocity varied between 353 and $417 \mathrm{~km} / \mathrm{s}$ (see Figure 1f), resulting in a prevailing solar wind dynamic pressure in the range $0.7-2.2 \mathrm{nPa}$ (see Figure $1 \mathrm{~g}$ ). We have highlighted the interval of interest in this study (0830-0835 UT, lagged time) by the vertical red dot-dash lines and the shaded area. During this highlighted interval, the IMF $B_{Z}$ and $B_{X}$ were mainly positive and IMF $B_{Y}$ was always negative, resulting in the IMF clock angle mainly varied between -90 and $-60^{\circ}$.

\subsection{THEMIS Observations Overview}

[9] The in situ time series measurements studied here are taken from the THEMIS spacecraft, while moving outbound from the Earth's morning sector magnetosphere at low latitudes (GSM coordinates $\mathrm{X}_{\mathrm{GSM}} \approx 8.5 R_{\mathrm{E}}, \mathrm{Y}_{\mathrm{GSM}} \approx-8.1 R_{\mathrm{E}}$, $\mathrm{Z}_{\mathrm{GSM}} \approx 0.1 R_{\mathrm{E}}$ ). Figure 2 shows an overview of the THEMIS FGM magnetic field data and ESA energy-time spectrograms for electrons during the interval of 0530-0900 UT on 26 August 2007. The magnetic field data are expressed in local 


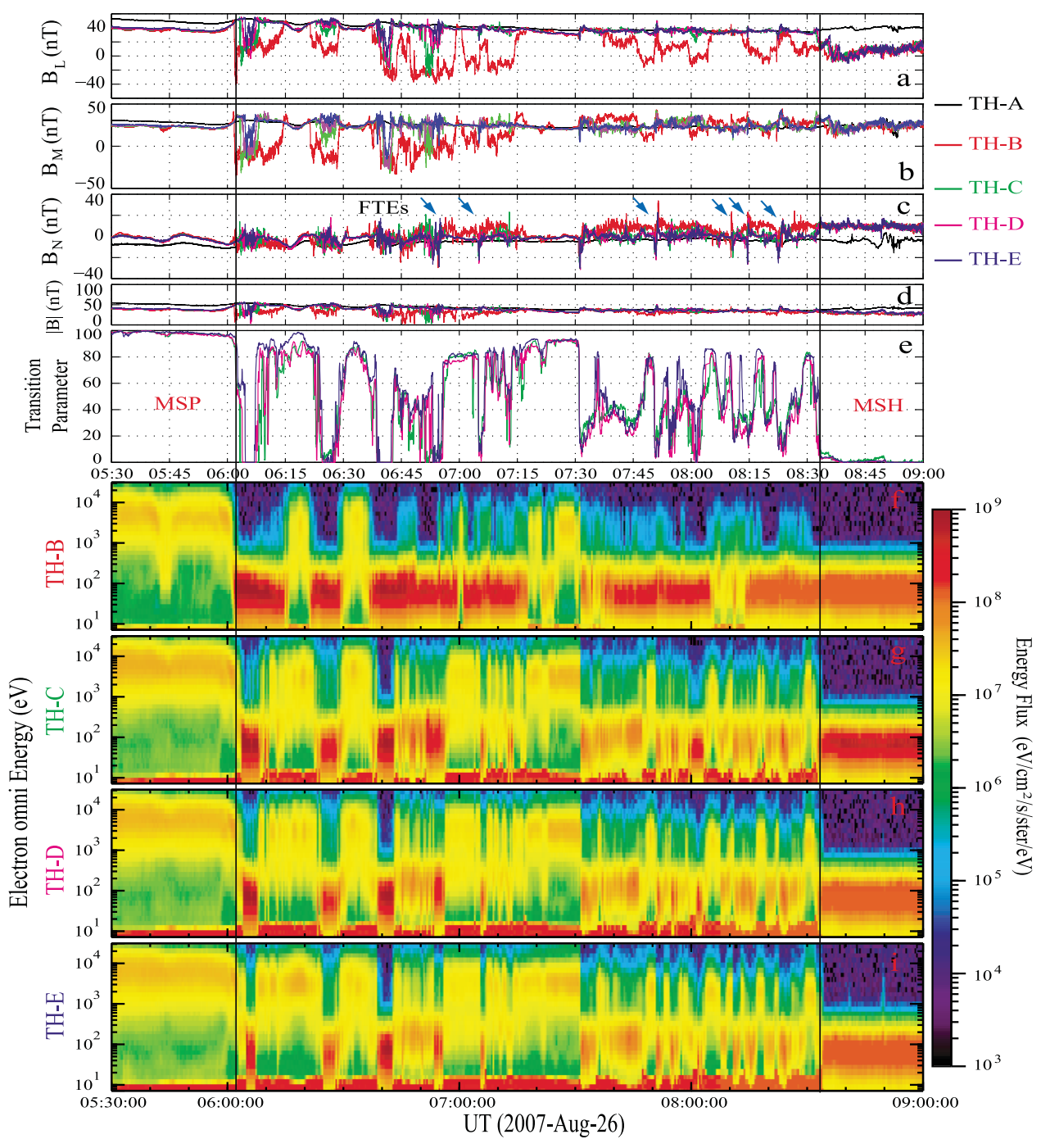

Figure 2. (top) An overview of the THEMIS FGM magnetic field measurement, presented in the boundarynormal (LMN) coordinate system, data from TH-A, TH-B, TH-C, TH-D and TH-E are shown in black, red, green, mauve and blue, respectively: (a) $B_{\mathrm{L}}$, (b) $B_{\mathrm{N}}$, (c) $B_{\mathrm{M}}$, and (d) $|B|$. The transition parameter obtained from the fitted plasma bulk electron density, $\mathrm{n}_{\mathrm{e}}$ and perpendicular electron temperature, $\mathrm{T}_{\mathrm{e} \perp}[$ Hapgood and Bryant, 1990]. (bottom) Energy-time spectrograms for electrons from (f) TH-B, (g) TH-C, (h) TH-D and (i) TH-E. The vertical black lines highlight the edges of the low-latitude boundary layer (LLBL) and the center of the current sheet (see text for details), and the typical FTEs are marked by the green arrows.

boundary normal coordinates (LMN), which are found by performing the minimum variance analysis (MVA) on the local magnetopause crossing of TH-C between about 0830 and 0835 UT to obtain the mean boundary normal $\mathbf{n}$, where $\mathbf{l}=(0.33$, $0.67,0.67), \mathbf{m}=(-0.36,-0.56,0.74)$ and $\mathbf{n}=(0.87,-0.49$, 0.06 ) in the GSM coordinates. This boundary normal direction is typical for the location of TH-C on the magnetopause. The transition parameters (TP) are presented in Figure 2e, which are obtained from the fitted plasma bulk electron density, $\mathrm{n}_{\mathrm{e}}$ and perpendicular electron temperature, $\mathrm{T}_{\mathrm{e} \perp}$ [Hapgood and Bryant, 1990] (see Figure 3a). We explain the derivation of the TP below. Figures $2 \mathrm{f}, 2 \mathrm{~g}, 2 \mathrm{~h}$, and $2 \mathrm{i}$ show energy-time spectrograms for electrons from TH-B, TH-C, TH-D and TH-E, respectively. The vertical black lines highlight the first crossing into the low-latitude boundary layer (LLBL) from the magnetosphere and the last crossing of the LLBL when the SC enter the magnetosheath, and the typical FTEs are marked by the blue arrows.

[10] The THEMIS spacecraft repeatedly cross through the magnetopause plasma boundary layer during the interval 0530-0900 UT on 26 August 2007 (as shown in Figure 2), finally crossing the dusk flank magnetopause into the magnetosheath at about 0832 UT. The four leading spacecraft (THEMIS B-E) exited into the magnetosheath in a bunched configuration, while the trailing spacecraft, THEMIS-A, followed sometime later. Figure 1 shows that the crossing of the dawn flank magnetopause occurred during conditions where the interplanetary magnetic field (IMF) was directed largely westward, with relatively small north/south fluctuations, while the solar wind pressure was generally 

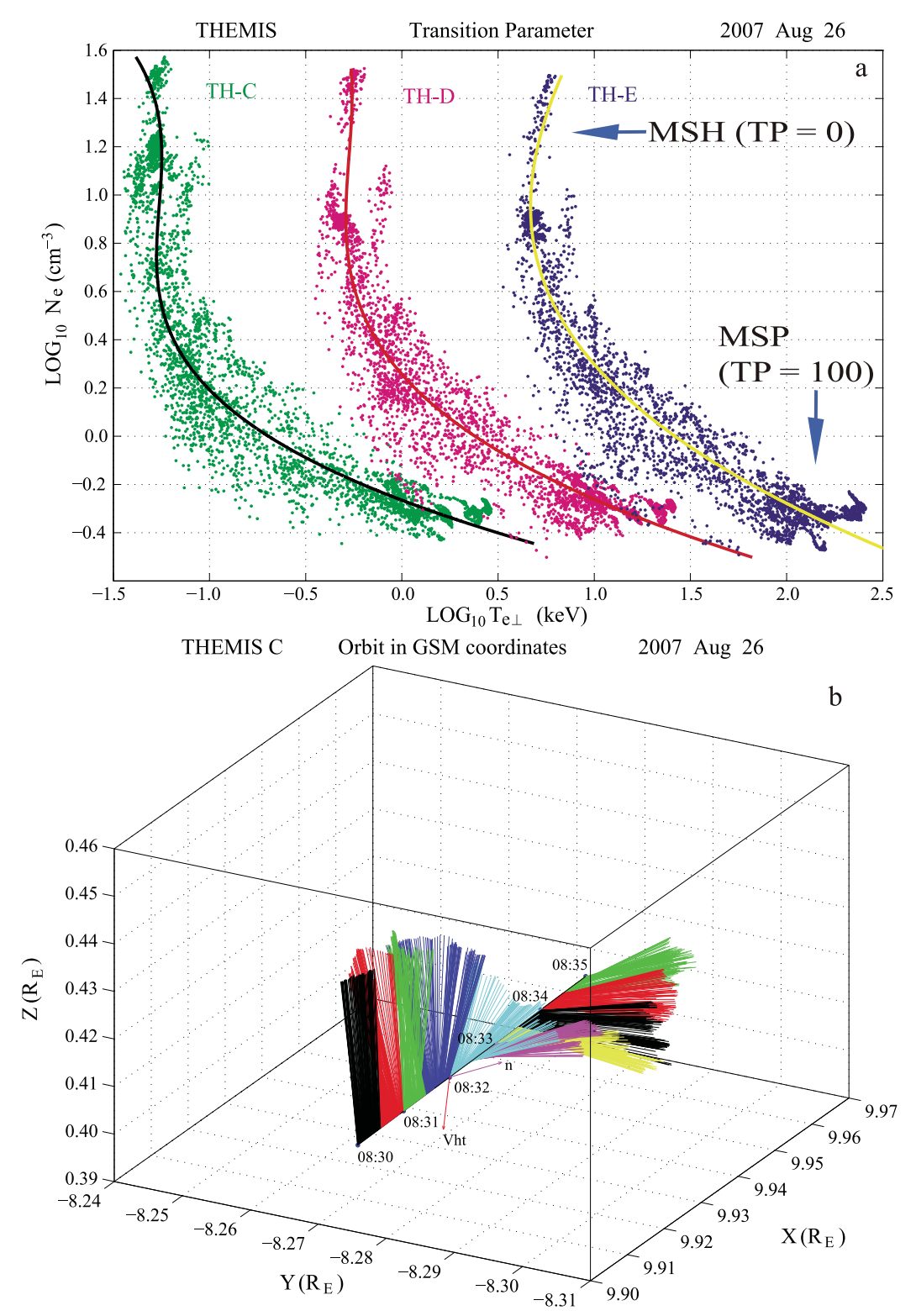

Figure 3. (a) The variation of electron density with perpendicular electron temperature (on a log-log scale) for magnetopause crossings by THEMIS C, D and E during the interval 05:30-09:00 UT: for clarity, the data for different spacecraft has been shifted by 1 along the $\log _{10}\left(T_{e \perp}\right)$ scale to separate them. (b) $3 \mathrm{D}$ orbit tracks of the THEMIS C probe in GSM coordinates, together with magnetic field vectors for every 30s colored, between 0830 and 0835 UT on 26 August 2007. The red and magenta vectors (with arrows) present the directions of deHoffmann-Teller frame velocity (Vht) and the mean boundary normal $\mathbf{n}$ which has been found by performing minimum variance analysis (MVA) on the local magnetopause crossing of TH-C between about 0830 and 0835 UT.

low (see in Figure 1g). As a result, the traversal through the plasma boundary layer was slow and over the extended period. Figures $2 \mathrm{~g}, 2 \mathrm{~h}$ and $2 \mathrm{i}$ show that three of the spacecraft C, D and E (being closest together) sampled the boundary layer repeatedly, while Figure $2 \mathrm{f}$ shows that the leading spacecraft $B$ generally remained in the magnetosheath and was there whenever $\mathrm{C}, \mathrm{D}$ or $\mathrm{E}$ encountered the magnetopause. THEMIS-A remained inside the magnetosphere during this period. Figure 2 shows that the spacecraft moved repeatedly in and out across the magnetopause with several clear FTEs (defined by the characteristic bipolar $\mathrm{B}_{\mathrm{N}}$ signature) so that alternately magnetospheric (low density, high temperature band with energies above $700-800 \mathrm{eV}$ ), and then magnetosheath-like (high density, low temperature band with energies below 300-400 eV) electron populations are observed at most (but not all) times when the magnetic field changed from its magnetospheric to the magnetosheath orientation. Thus, the times when a magnetosheath-like population appeared without a change in the $\mathrm{B}_{\mathrm{L}}$ component show entries into the boundary layer inside the magnetopause. Furthermore, the electron plasma distributions, shown in Figures $2 \mathrm{f}-2 \mathrm{i}$, 
were changing as the traversal continued, resulting from the different degrees of mixing between the plasma populations. These changes are most obvious between the vertical lines drawn on the plot where the distribution is particularly distributed across the whole energy range. The $\mathrm{B}_{\mathrm{M}}$ component of the magnetic field was also seen to change its character at these times, which reflects a twisted topology of the magnetic field.

[11] Despite the dynamic nature of both the field and plasma distributions during this interval, the plasma bulk character is surprisingly well ordered in the following sense: a plot of the electron density and temperature are well ordered and very similar for each spacecraft, as shown in Figure 3a. The spacecraft were repeatedly moving from a magnetospheric region of high temperature and low density to a magnetosheath population of low temperature and high density. The scatterplots are of the integrated electron data, giving plasma bulk electron density, $\mathrm{n}_{\mathrm{e}}$ and perpendicular electron temperature, $\mathrm{T}_{\mathrm{e} \perp}$ during the interval of 0530-0900 UT for probes $\mathrm{C}, \mathrm{D}$ and $\mathrm{E}$ (each with an offset of $10 \mathrm{keV}$ along the $\log \mathrm{T}$ axis for clarity), but note that there is no electron density and temperature data for $\mathrm{TH}-\mathrm{B}$ in the interval of interest. These can be well fitted to the transition parameter (TP), introduced by Hapgood and Bryant [1990] and drawn as a curved fit to each data set (After projecting each data point onto the curve by finding the point on the curve closest to the data point, a raw TP corresponding to each data point was calculated by determining the distance along the curve from the projected point to an arbitrary origin beyond the magnetosheath end of the distribution, and then the values of TP were normalized to range 0 to 100 .). This parameter can define positions within the boundary layer depending on the plasma mixing: [Lockwood and Hapgood, 1997] showed how the plasma mixing, and hence the TP depends on the time elapsed since reconnection in an open LLBL that results from magnetic reconnection. Low values (typically $\mathrm{TP}<20$ ) indicate the spacecraft is located in the magnetosheath, while high values (typically TP $>80$ ) indicate the spacecraft is located in the magnetosphere [Bogdanova et al., 2008]. Figure 2e shows this parameter, derived for each spacecraft separately, and reveals that, not only were the spacecraft moving rapidly back and forth through the boundary layer, giving nested signatures in $\mathrm{TP}$, but that each spacecraft records the same value of $\mathrm{TP}$ at the same $\mathrm{B}_{\mathrm{L}}$ position (we show this in more detail in later figures), confirming that the TP orders well the structure either side of the magnetopause. Hence, the boundary structure was relatively constant in space during this interval, but was moving in and out rapidly to give multiple intersections, showing temporal variations. Some of the changes take place rapidly compared to the instrument time resolution during the backward and forward magnetopause crossings, giving discreet jumps in the observed data.

[12] The final exit into the magnetosheath (between about 08:30-08:35 UT), however, was relatively slow and so the full reconnection layer was observed. Figure $3 \mathrm{~b}$ shows $3 \mathrm{D}$ orbit tracks of the THEMIS C (TH-C) probe for this smaller interval in GSM coordinates, together with magnetic field vectors for every 30s colored, between 0830 and 0835 UT on 26 August 2007. The red and magenta vectors (with arrows) present the directions of deHoffmann-Teller frame velocity (Vht) and the mean boundary normal $\mathbf{n}$ which has been found by performing minimum variance analysis (MVA) on the local magnetopause crossing of $\mathrm{TH}-\mathrm{C}$ between about 0830 and 0835 UT. The Vht and $\mathbf{n}$ vectors in GSM coordinates are $[-13.83,-1.09,-67.82] \mathrm{km} / \mathrm{s}$ and $[0.87,-0.49,0.06]$, respectively. The angle between Vht and $\mathbf{n}$ is about $103^{\circ}$ and hence the in-boundary flow greatly exceeds the in-out boundary motion speed. Assumed the flow comes from the reconnection X-line, Vht has a larger southward component showing the reconnection site was to the north of the satellites (i.e., in the Northern Hemisphere), but also a component in the $-\mathrm{Y}$ direction, showing the reconnection site was on the noon-ward side of the satellites (which were near $9 \mathrm{MLT}$ ). The magnetic field rotated from northward to westward at about $0832 \mathrm{UT}$, indicating that $\mathrm{TH}-\mathrm{C}$ crossed through the dawn flank magnetopause into the magnetosheath at this time. The detail of the magnetic field line behavior will be addressed in the discussion.

\subsection{THEMIS Observations: Last Boundary Layer Crossing}

[13] Figure 4 shows the magnetic field and, plasma and electric field spectrum data for the interval of 0830-0835 UT from TH-C spacecraft, together with the IMF clock angle observed by ACE (lagged by $77.86 \mathrm{~min}$ ) and the magnetosheath field clock angle seen by TH-B. The vertical lines marked ' $\mathrm{P}$ ', ' $\mathrm{Q}$ ', ' $\mathrm{R}$ ', and ' $\mathrm{S}$ ' define where TH-C intersects the inferred open-closed field line boundary (the outer edge of purely magnetospheric plasma), the magnetospheric boundary, the center of the current sheet (magnetopause) and magnetosheath boundary (the inner edge of purely magnetosheath plasma), respectively. These boundaries (' $\mathrm{P}$ ', ' $\mathrm{Q}$ ', ' $R$ ', and ' $S$ ') are identified by the sharp boundaries in the electron anisotropy data (Figure 4i) and in the FBK electric field spectrum data (Figure 4j). During the interval of interest, the IMF clock angle varied between -90 and $-60^{\circ}$, which is believed to be favorable for the occurrence of lobe reconnection poleward of the cusp region and simultaneous low-latitude reconnection at the flank magnetopause [Lockwood and Moen, 1999; Pu et al., 2007; Trattner et al., 2007; Dunlop et al., 2011]. Noting that the magnetosheath clock angle observed by TH-B sometimes disagreed with the IMF clock angle as TH-B sometimes went to the boundary layer. The magnetic field and ion velocity data are expressed in the LMN coordinates (same coordinates as in Figure 2). The electron density $N_{e}$ was very close to ion density $N_{i}$, except that $\mathrm{N}_{\mathrm{e}}$ was sometimes very slightly $\left(\sim 0.4 \mathrm{~cm}^{-3}\right)$ higher than $\mathrm{N}_{\mathrm{i}}$ between $\mathrm{R}$ and $\mathrm{S}$ : this difference was small compared to measurement uncertainties.

[14] The magnetic field and plasma panels (including the energy spectra) show the progressive transition from the magnetospheric to the magnetosheath distribution with a clear boundary layer in the middle, surrounding the current sheet (note that the change in TP is almost, but not quite, monotonic). Mixed high- and low-energy electron populations are apparent in each sublayer, which faded away as the magnetosheath boundary $\mathrm{S}$ was approached. A significant degree of structure is seen centered on the current sheet $\mathrm{R}$. Note that photoelectron contamination with energies below $25 \mathrm{eV}$ are present before about 0832:30 UT (see Figures 4g and $4 \mathrm{~h}$ ). Before line $\mathrm{P}$, the TP is above 90 and the plasma showed characteristics of the magnetosphere, i.e., plasma at magnetospheric energies, together with an anisotropic 
distribution at low energies $(\sim 100 \mathrm{eV})$, which was strongly field-aligned. After line S, the TP is below 10, corresponding to the magnetosheath which shows a nearly isotropic (balanced electron anisotropies) inflowing lower-energy plasma (below about $100 \mathrm{eV}$ ) and an absence of high energy magnetospheric electrons. We note that the magnetosheath after line $\mathrm{S}$ has a significant anti-parallel electron population at energies ranging of about $100-400 \mathrm{eV}$ (see electron

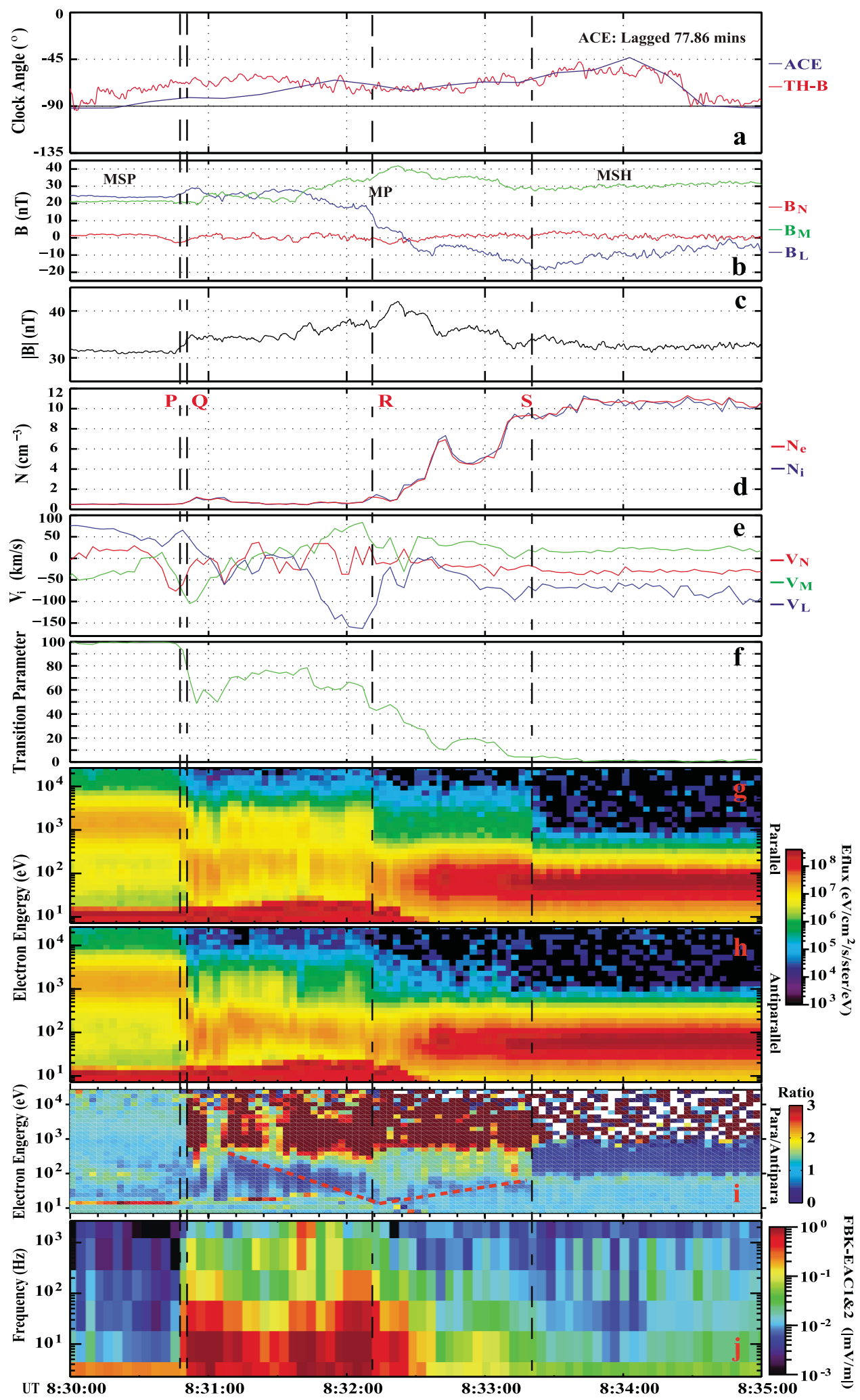

Figure 4 
anisotropy in Figure 4i), which might be because the antiparallel electrons were locally accelerated or heated by the dayside magnetopause current sheet or thin current sheet in the magnetosheath near magnetopause.

[15] Between P and Q, the TP decreases from about 90 to 70 and the distributions show bi-directional streaming (field aligned) populations of electrons (with high parallel-to-perpendicular anisotropy, not shown). Some energy dispersion was observed starting at $\mathrm{P}$ where part of the magnetospheric electrons started to be lost and the magnetosheath electrons started to flow in. A sharp boundary was identified at $\mathrm{P}$ as the separatrix on the magnetosphere side $\left(\mathrm{S}_{\mathrm{sp}}\right)$ in FBK E spectrum data which is consistent with the results reported by Retinò et al. [2006]. Figure 4i shows that between $\mathrm{P}$ and $\mathrm{Q}$ the parallel-to-antiparallel anisotropy was close to unity at all energies, which might be the region between the separatrix and the electron edge. The electron edge is not well identified in the spectrum data with $3 \mathrm{~s}$ resolution, which is due to the large velocity of electrons leading the electron edge located very close to the separatrix [Vaivads et al., 2010]. At Q, the electrons showed a sharp boundary in the anisotropy data (see Figure 4i) and the electric field reached its maximum of about $1.35 \mathrm{mV} / \mathrm{m}$ at the frequency band around $10 \mathrm{~Hz}$ in the E spectrum, indicating that the spacecraft crossed the Alfvén wave (or "rotational discontinuity, $\mathrm{RD})$ which is formed on the both side of the current sheet when there is a large difference in the Alfvén speed $\mathrm{V}_{\mathrm{A}}$ in the fluid description [Nakamura and Scholer, 2000], and is launched from the reconnection site and stands in the inflow on the lower density (magnetosphere) side of the boundary $\left(\mathrm{RD}_{\mathrm{sp}}\right)$ [Lockwood, 1997]. The lower density in the magnetosphere means that field lines moved along $\mathrm{RD}_{\mathrm{sp}}$ more rapidly than for its counterpart standing in the inflow from the magnetosheath side of the boundary $\left(\mathrm{RD}_{\mathrm{sh}}\right)$. The $\mathrm{RDsh}$, highlighted by the vertical dashed line and marked by R, is identified by the sharp boundary in the electron anisotropy (Figure 4i) and the electric field spectrum (Figure 4j) together with the magnetic field $\mathrm{B}_{\mathrm{L}}$ component rotating its sign from positive to negative (there is a little shift in $B_{L}$ which might be because of the background field). Between $R D_{\text {sp }}$ and $R D_{\text {sh }}$, there can be a variety of slower Alfvénic disturbances which caused the field to rotate from the magnetospheric to magnetosheath orientation (see Figure 3) [Heyn et al., 1988; Lockwood and Hapgood, 1998]. The elapsed time since reconnection peaks when the spacecraft was at the center of the current sheet, somewhere between $\mathrm{RD}_{\mathrm{sp}}$ and $\mathrm{RD}_{\mathrm{sh}}$. (Note that without the slower Alfvénic disturbances the current sheet would be at $\mathrm{RD}_{\mathrm{sh}}$ because the larger densities on this side of the boundary mean that the Alfvén speed is lower [Lockwood, 1997].) The deHoffmanTeller velocity derived from the stress balance analysis shows that TH-C was southward and dawnward of the Xline (Figure 3) and the field orientation indicates that parallel/antiparallel fluxes corresponded to particles flowing out/ into the magnetosphere. The normal component of $\mathbf{V h t}$ and the duration of the $\mathrm{RD}_{\mathrm{sp}}$ to $\mathrm{RD}_{\mathrm{sh}}$ crossing (about $11 \mathrm{~s}$, deducting the intervals when TH-C was out of the region between the RDs), give a rough estimated thickness of the boundary layer of about $170 \mathrm{~km}$. If we assume the reconnection rate is on the order of 0.1 , we then roughly estimate the distance from TH-C to the X-line by 10 times of the boundary layer thickness, which is about $9 \mathrm{c} / \omega_{\mathrm{pi}}$, indicating that TH-C was not too far from the X-line.

[16] Between $\mathrm{Q}$ and $\mathrm{R}$, the TP rises from 60 to 80 and then falls back to 60 (Figure 4f), showing that the boundary moved slightly and briefly out over the spacecraft, making it return slightly toward $\mathrm{RD}_{\mathrm{sp}}$ before again moving toward the magnetosheath (which will be addressed in some detail in the discussion). The parallel/anti-parallel anisotropy shows that the bi-directional populations disappeared after Q and the magnetospheric population (seen at energies above about $200 \mathrm{eV}$ ) became strongly out-flowing (field parallel: dark red in Figure 4i). At the same time, below about $200 \mathrm{eV}$ the anisotropy became strongly in-flowing (field anti-parallel: blue in Figure 4i). This unambiguously reveals open field lines with magnetosheath electrons entering the magnetosphere and magnetospheric electrons leaving it. Between Q and $\mathrm{R}$ the energy of the balanced parallel and antiparallel electron fluxes (green contour in Figure 4i) fell gradually as increasingly lower energy magnetosheath electrons began to mirror at low altitudes and returned to the spacecraft. It is worth noting that the ion velocity shows a flow burst (plasma jet) just inside the center of the structure (near R) in the $-\mathrm{L}$ direction (Figure 4e) associated with deflected and accelerated plasma [Eastwood et al., 2010]. Between 'R' and ' $\mathrm{S}$ ', both the ion and electron densities begin increasing within a clear density cavity together with an enhanced $\mathrm{B}_{\mathrm{M}}$ between about 0832:43 and 0833:09 UT. The TP decreases from about 40 to 5 as time elapsed since reconnection fell again (until it is zero at $S$ ). In this region (between $R$ and $S$ ) magnetospheric electrons detected by the spacecraft were outgoing, as expected for open field lines on this side of the $\mathrm{RD}_{\mathrm{sh}}$. Interestingly, magnetosheath electrons also show flows predominantly away from the magnetopause, indicating that although magnetosheath electrons were crossing the $\mathrm{RD}$ and entering the magnetosphere, a considerable fraction might be being reflected by the RD and by the polar ionosphere and returned to the magnetosheath along the reconnection flux tube: only at the lowest energies (around $50 \mathrm{eV}$ ) is there a band of blue (see in Figure 4i) showing net flow toward the RD. The upper energy of this band increased slightly in energy between $\mathrm{R}$ and $\mathrm{S}$, similar to that dispersion

\footnotetext{
Figure 4. Plasma, electric field spectrum and magnetic field data in the boundary-normal (LMN) coordinate system from THC spacecraft, together with the IMF conditions, during 0830-0835 UT on 26 August 2007. Parameters are (a) the IMF clock angle measured by the ACE satellite (lagged by $77.86 \mathrm{~min}$ ) and the TH-B spacecraft, (b) the three components of the magnetic field measurement in LMN coordinates, (c) the magnitude of the magnetic field, (d) the ion and electron number density, (e) the ion velocity in LMN coordinates, (f) the transition parameter, $(\mathrm{g}$ and $\mathrm{h}$ ) the energy-time electron spectrograms in the parallel and anti-parallel directions, (i) the electron anisotropy of the parallel/anti-parallel energy flux, and (j) the spectrogram electric field AC component sensors 1 and 2 from FBK data, respectively. The black vertical dashed lines highlight the boundaries of the different regions of the boundary layer denoted $\mathrm{P}, \mathrm{Q}, \mathrm{R}$, and $\mathrm{S}$ (see text form details). The red dashed lines are drawn to show the approximate $\mathrm{V}$-shape in the energy in Figure 4i for guiding the eye.
} 
on the magnetosphere side of $\mathrm{R}$. The data therefore show that TH-C crossed the whole reconnection layer, in which, at higher energies, the electrons were dominated by the flow toward the $\mathrm{X}$-line in the magnetospheric $\mathrm{BL}$ and away from the $\mathrm{X}$-line in the magnetosheath BL. It is worth noting that the anisotropies showed an approximate V-shape in the energy at which fluxes of incoming sheath electrons and outgoing magnetosphere electrons were balanced, with the minimum of that "V" near R, which is shown by red dashed lines in Figure 4i to guide the eye. This implies the most newly reconnected field lines were at both edges (near Q and S) and the oldest ones (for which lower energy sheath electrons have mirrored and returned to the satellite) were seen at the center of the reconnection layer, which confirms the concept of particle populations in the low-latitude reconnection layer evolving with time-elapsed since reconnection. The final exit into magnetosheath at $\mathrm{S}$ is marked by the complete absence of magnetospheric electrons. The open/ interplanetary field line boundary must be close to, but just after S (but will not be marked by any signature as particles cannot travel along this separatrix at infinite velocity).

\subsection{Analysis of the Plasma Distributions}

[17] In Figure 5, we plot a summary of the electron spectra inside the different plasma regions identified above. The black, red and green lines present the cuts of electron spectra in the parallel, perpendicular, and anti-parallel directions. The high and low energy plasma of the magnetospheric populations (seen before $\mathrm{P}$ in Figure 5a) were very well balanced in parallel and anti-parallel directions (bi-streaming), but were not balanced in perpendicular and parallel/ anti-parallel, which indicate electron trapping on the closed field lines. A distinct bi-streaming population was seen to peak at around $70 \mathrm{eV}$, which was usually interpreted as originating in the two ionospheres or trapped from magnetosheath a very long time ago. The same form of anisotropic distribution was seen between the perpendicular and fieldaligned directions between $\mathrm{P}$ and $\mathrm{Q}$ but the bi-streaming low energy electrons extended up to higher energies (above around $150 \mathrm{eV}$, see Figure 5b) which could be interpreted as trapped magnetosheath electrons mirrored backward and forwards between the separatrices at the magnetospheric side [e.g., Egedal et al., 2010; Wang et al., 2010a, 2010b; Huang et al., 2010]. Between $\mathrm{Q}$ and $\mathrm{R}$, the electron populations were dominated by outgoing (parallel) magnetospheric electrons and ingoing (antiparallel) magnetosheath populations, which is the typical plasma feature on open field lines associated with the low-latitude reconnection (Figure 5c). At $R$ (see Figure $5 \mathrm{~d}$ ), the electrons were still dominated by strong outgoing magnetospheric electrons but we now see bi-streaming magnetosheath populations as the incoming sheath population had been joined by a population that had mirrored at some point near the magnetopause. Here we assume the inward Hall E-field may play a role in reflecting sheath electrons, and/or Langmuir waves as reported by Vaivads et al. [2004] may play a role in heating/thermalizing electrons. As this second population travels to the mirror point and back to the satellite, this feature is associated with older reconnected field lines. Figure $5 \mathrm{e}$ shows that the between $\mathrm{R}$ and $\mathrm{S}$ electrons were still dominated by outgoing magnetospheric electrons and ingoing magnetosheath populations, which were also associated with electron spectra at the newly open field lines in the magnetosheath branch of the reconnection layer. In the magnetosheath (after S), the low-energy part of the plasma population had greater fluxes than seen in the boundary layers with a complete absence of magnetospheric electrons. This supports the inference made above that some fraction of the magnetosheath electrons on open field lines was reflected at the magnetopause rather than being transmitted across it.

[18] In order to investigate further the plasma structure inside the reconnection layer, in Figure 6 we plot the energytime ion spectrograms in the parallel, anti-parallel and perpendicular directions. The red vertical dashed lines highlight the ion boundary layer (BL), which is well defined by the accelerated magnetosheath ions in the anti-parallel (inward) direction (pitch angle, pa $\sim 180^{\circ}$ ) and corresponds to electron transition parameters of about 30-60 (between the two horizontal thick black dashed lines in the second panel of Figure 6) and are marked by ' $a$ ' in the ion spectrograms. The last red vertical dashed line, marked by $\mathrm{R}^{\prime}$, is the last crossing of the $\mathrm{RD}_{\text {sh }}$ because part of the reconnection layer moved back and forth across TH-C during the interval of interest. The shear angle of magnetic field between TH-B (who was located in magnetosheath seen in Figure 2) and TH-C is presented in the first panel of Figure 6, which shows the average shear angle was about $60^{\circ}$ between the magnetospheric and magnetosheath field lines during the TH-C reconnection layer crossing. This confirms that a lowlatitude reconnection layer can be present even for shear angles of $\sim 60^{\circ}$ as reported by Scurry et al. [1994] and Phan et al. [2005]. From the bottom three spectrograms, we find that the ion entry region straddled the main RD (the magnetopause) and note the dispersed loss of field aligned and field perpendicular magnetospheric ions (marked by ' $b$ ') as reconnection cuts off the source of such ions to the spacecraft. We also note the dispersed arrival of field aligned and perpendicular magnetosheath ions marked by ' $c$ '. Because in the sheath boundary layer (between R and S) elapsed time since reconnection was decreasing with observation time, this corresponds to a dispersed loss of field aligned and perpendicular magnetosheath ions with increasing time elapsed since reconnection. This shows that reconnection had cut off the source of such ions such that below a cut-off energy (which increases with increased time elapsed since reconnection) ions cannot reach the sheath boundary layer in this case. We infer that this is because the sheath field is largely draped along the magnetopause and there is strong sheath flow in the field-parallel direction in the Earth rest frame. In the absence of reconnection this field-aligned flow would supply the ions to this region: however the reconnection has cut off this supply.

\section{Discussion and Conclusions}

[19] From Figure $4 d$, we found that there was a clear density cavity together with an enhanced $\mathrm{B}_{\mathrm{M}}$ between about 0832:43 and 0833:09 UT. These observations do not agree with the 2 dimension (2D) Hall reconnection simulation results of a single density cavity only appearing on the northern magnetosheath side of the reconnection layer and a reducing $\mathrm{B}_{\mathrm{M}}$ on the southern side of the $\mathrm{X}$-line during strong guide field conditions [Pritchett and Mozer, 2009]. These differences might suggest three possible explanations of this 


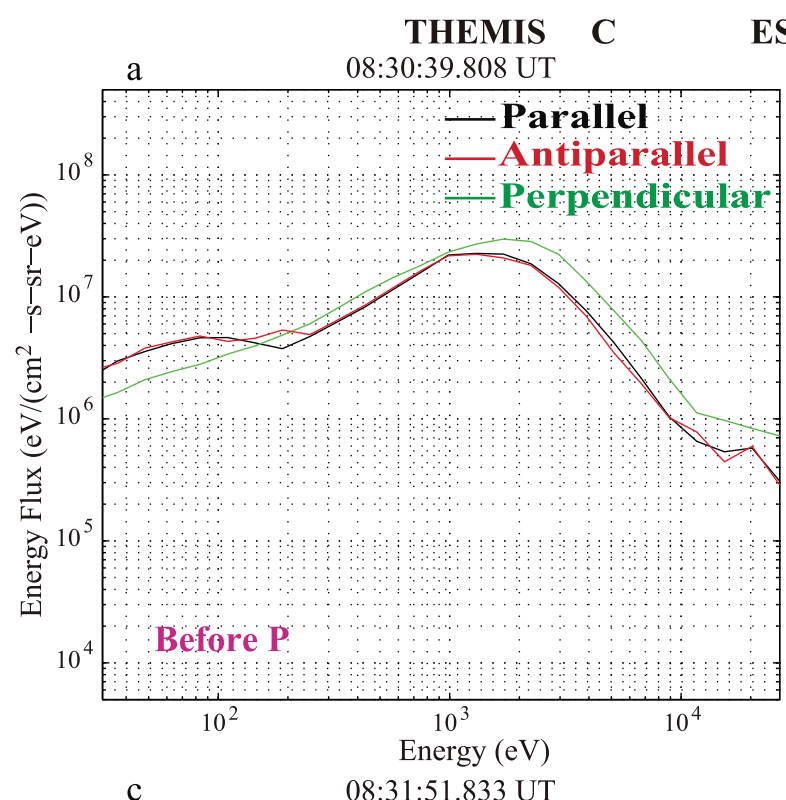

ESA Electrons DATA

26 Aug 2007
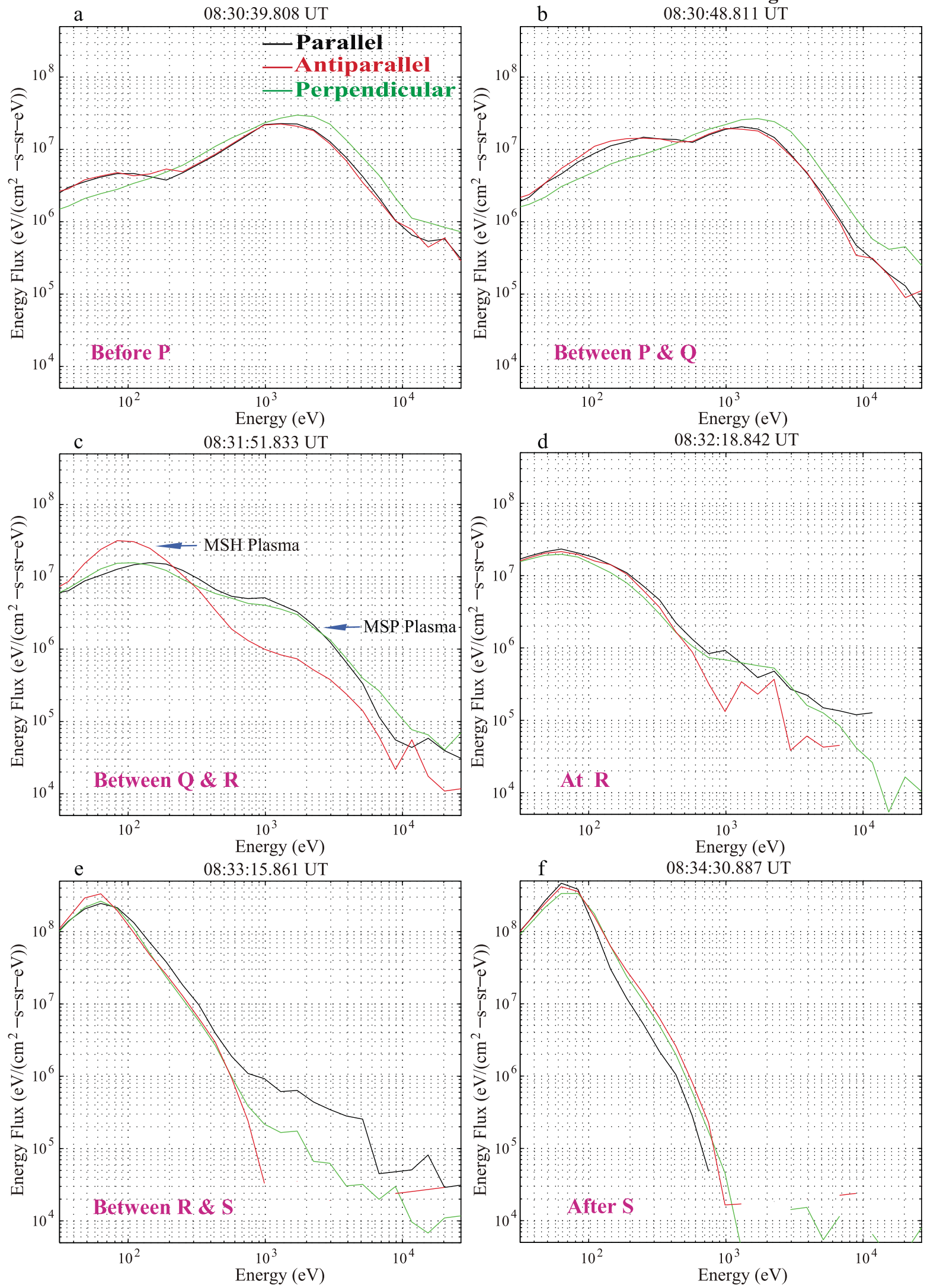

Figure 5. A summary of the typical electron spectra from TH-C inside the different plasma regions defined in Figure 3. The black, red and green lines present the cuts of electron spectra in the parallel, perpendicular, and antiparallel directions. 


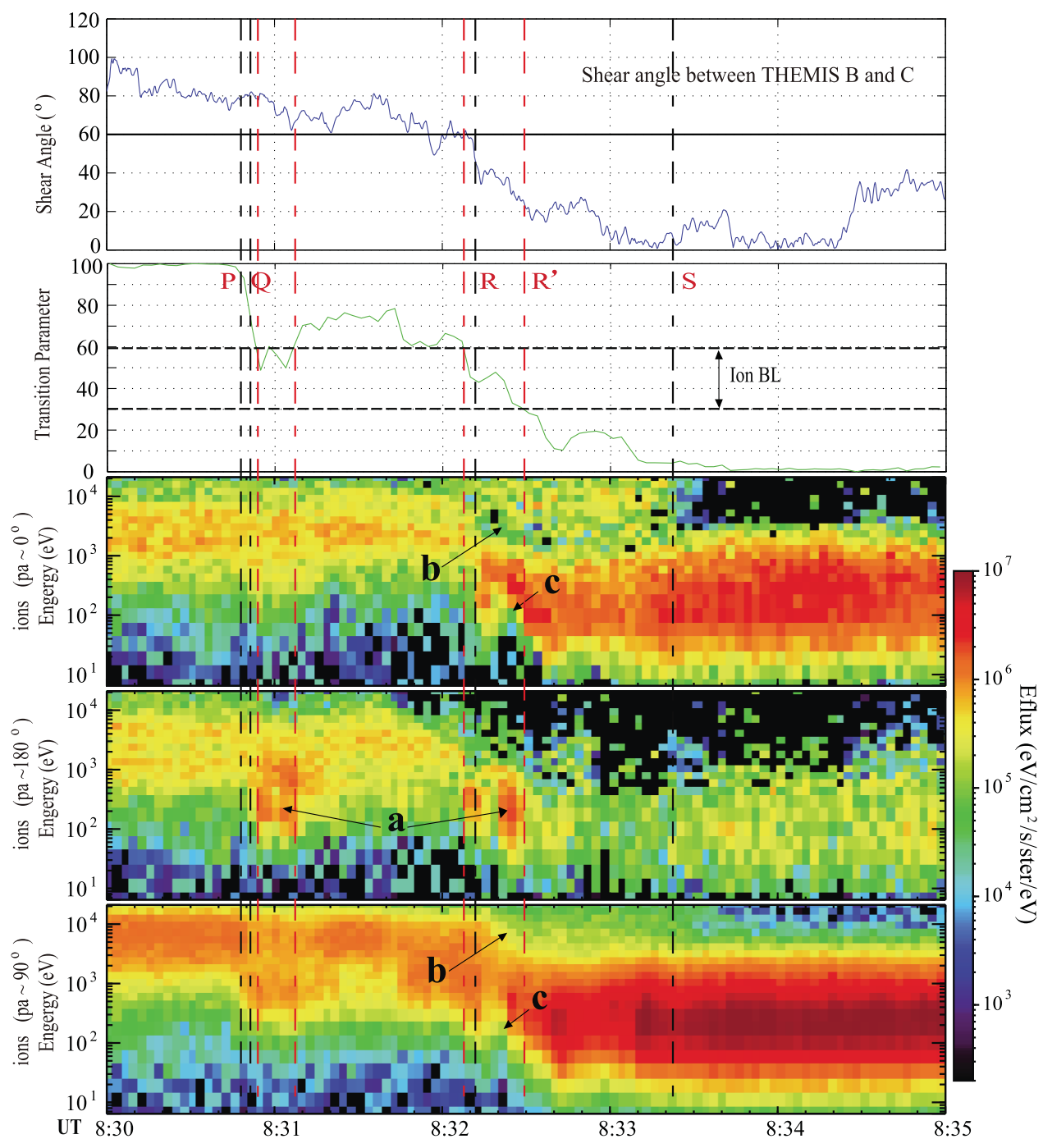

Figure 6. The energy-time ion spectrograms in the parallel, anti-parallel and perpendicular directions, together with the shear angle of magnetic field between TH-B and TH-C, and the transition parameter same as Figure 3e.

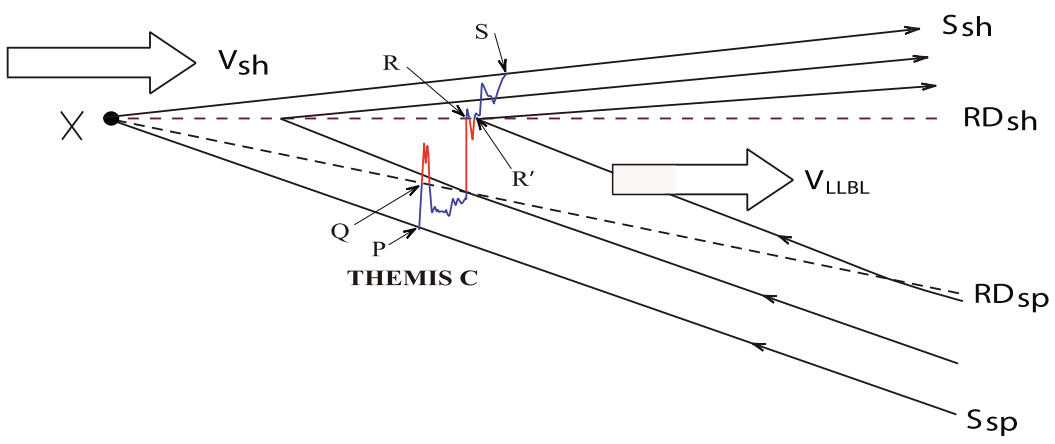

Figure 7. Schematic of tracks of TH-C in the open LLBL between the magnetic separatrices in both magnetosphere and magnetosheath sides emanating from the reconnection site (X-line), X. Field lines evolving away from $\mathrm{X}$ are shown at three elapsed times since they were opened. The dashed lines are the rotational discontinuities (RDs) standing on the inflow on the magnetosheath and magnetosphere sides, respectively. The blue and red tracks present TH-C is located out of the RDs and between the $\mathrm{RDs}$, respectively. 
density depletion layer. First, such features were the consequences of $3 \mathrm{D}$ evolution of the reconnection layer, possibly due to the presence of significant sub-Alfvénic sheath flows twisting the reconnected field lines threedimensionally. Second, considering the pressure balance, the flux tube just outside the magnetopause would expand because of the hot magnetospheric ions which exert a higher thermal pressure. The expansion in turn reduces the density. Third, if the thermal speed of sheath ions is comparable or larger than the sheath Alfvén speed, then the effects of reconnection on the magnetosheath side would appear first as a cut off of sheath ions with a super-Alfvénic parallel speed (in the sheath plasma rest frame), possibly partly reducing the density, and then as $\mathrm{RD}_{\mathrm{sh}}$.

[20] As the TP depends on the time elapsed since reconnection in an open LLBL resulting from MR [Lockwood and Hapgood, 1997], we use TP to estimate TH-C passing through the BL allowing for in-out motions in the $\mathrm{N}$ direction. In Figure 7, we track TH-C passing on a standard reconnection outflow fan with RD's (dashed lines) standing in the inflow from both sides $\left(\mathrm{RD}_{\mathrm{sh}}\right.$ (the magnetopause) on the magnetosheath side and $\mathrm{RD}_{\mathrm{sp}}$ on the magnetosphere side). The separatrices are $\mathrm{S}_{\mathrm{sh}}$ and $\mathrm{S}_{\mathrm{sp}}$. The blue and red lines are nonlinear, but monotonic, distortions of the transition parameter variation with time. All magnetosheath ions seen between $\mathrm{RD}_{\mathrm{sh}}$ and $\mathrm{RD}_{\mathrm{sp}}$ were sub-Alfvénic in the magnetosphere - i.e., they were seen between $\mathrm{Q}$ and $\mathrm{R}^{\prime}$. They were in a burst after $\mathrm{Q}$, a burst just before $\mathrm{R}$, and a final one between $\mathrm{R}$ and $\mathrm{R}^{\prime}$ (the red line).

[21] Between $\mathrm{R}$ and $\mathrm{S}$, TH-C was in the magnetopause boundary layer. The ion spectrum was topologically disconnected from the main source of magnetosheath ions which flow in the field-aligned direction, together with larger energy magnetospheric plasma, even if THC was on the most recently reconnected field lines in the magnetosheath boundary layer (near S). However, the lower energy ions are not observed in field-perpendicular direction at larger time elapsed since reconnection (which peaks at $\mathrm{R}$ and the brief return to the exterior $\mathrm{RD}, \mathrm{RD}_{\text {sh }}$, at $\left.\mathrm{R}^{\prime}\right)$. This is consistent with the dispersed appearance of magnetosheath ions in energy (and in pitch angle distribution - data not shown) as TH-C moved from $\mathrm{RD}_{\mathrm{sh}}$ to $\mathrm{S}_{\mathrm{sh}}$. This shows the same feature as the dispersed loss of field-antiparallel and field-perpendicular magnetospheric ions on the magnetosphere side of the reconnection layer with lower energy ions being lost as TH-C went deeper into the LLBL i.e., onto field lines with longer elapsed times since reconnection, when $\mathrm{TH}-\mathrm{C}$ moved from $\mathrm{S}_{\mathrm{sp}}$ toward $\mathrm{RD}_{\mathrm{sh}}$.

[22] Going back to the magnetosheath BL, we argue that the dispersed loss of magnetosheath ions in the magnetosheath BL set up an ion density gradient along the field lines to which electrons responded to (almost) cancel it out and maintained quasi neutrality, so electron density $\mathrm{N}_{\mathrm{e}}$ was close to ion density $\mathrm{N}_{i}$ between $\mathrm{R}$ and $\mathrm{S}$. However, we noted earlier that between $\mathrm{R}$ and $\mathrm{S}, \mathrm{N}_{\mathrm{e}}$ was sometimes very slightly $\left(\sim 0.4 \mathrm{~cm}^{-3}\right)$ greater than $\mathrm{N}_{\mathrm{i}}$. Measurement uncertainties prevent us for stating that this excess of electrons was definitely present, but were it so then it would form an effective field-aligned potential barrier over a very short distance which will accelerate ions inward (giving the parallel magnetosheath ions seen in the LLBL) and repelling magnetosheath electrons back into the magnetosheath. Because the barrier was moving at about $150 \mathrm{~km} / \mathrm{s}$ it would also mean the electrons reflected off it were slightly energized. For instance $400 \mathrm{eV}$ incoming (antiparallel) electrons would be accelerated to $410 \mathrm{eV}$ upon reflection, which is broadly consistent with the slight acceleration of the parallel magnetosheath electrons seen in the magnetosheath boundary layer between $\mathrm{R}^{\prime}$ and $\mathrm{S}$.

[23] We report a case study of THEMIS multispacecraft data from 26 August 2007 showing clear transitions through a low-latitude reconnection layer which shows a complete traversal across all reconnected field lines and the associated plasma populations at that distance from the reconnection site. The results confirm details of the electron and ion mixing, time history and flow across the current layer, and the particle populations in the reconnection layer evolving with time elapsed since reconnection. In the reconnection layer, there was a velocity dispersion effect in the electron anisotropy, together with two separatrices $\left(\mathrm{S}_{\mathrm{sp}}\right.$ and $\left.\mathrm{S}_{\mathrm{sh}}\right)$ and two $\mathrm{RD}\left(\mathrm{RD}_{\mathrm{sp}}\right.$ and $\left.\mathrm{RD}_{\mathrm{sh}}\right)$, which are consistent with the time elapsed since reconnection of the given field lines crossed. The observations also show that the reconnection layer had a single density cavity on the magnetosheath side, giving a sheath plasma depletion layer caused by nearly field-aligned magnetosheath flow. New evidence has also been given for the occurrence of partial reflection of magnetosheath electrons at the magnetopause which helps to maintain quasineutrality of the plasma populations despite the rapid evolution and mixing of sheath and magnetosphere plasmas on newly reconnected field lines.

[24] Acknowledgments. This work is supported by the National Basic Research Program of China (grant 2012CB825603), the National Natural Science Foundation of China (grants 41104091, 41031064, 40890164), the International Collaboration Supporting Project, Chinese Arctic and Antarctic Administration (IC201112), and Ocean Public Welfare Scientific Research Project, State Oceanic Administration People's Republic of China (201005017). Part of the work was done for the ISSI working group "Conjugate response of the dayside magnetopause and dawn/dusk flanks using Cluster-THEMIS conjunctions and ground based observations," which is led by M. W. Dunlop and Y. V. Bogdanova. M. W. Dunlop is partly supported by Chinese Academy of Sciences (CAS) visiting Professorship for senior international scientists (grant 2009S1-54). We acknowledge NASA contract NAS5-02099 and V. Angelopoulos for use of data from the THEMIS Mission. Specifically: C. W. Carlson and J. P. McFadden for use of ESA data and K. H. Glassmeier, U. Auster and W. Baumjohann for the use of FGM data provided under the lead of the Technical University of Braunschweig and with financial support through the German Ministry for Economy and Technology and the German Center for Aviation and Space (DLR) under contract 50 OC 0302.

[25] Masaki Fujimoto thanks Hui Zhang and another reviewer for their assistance in evaluating this paper.

\section{References}

Anderson, B. J., T. D. Phan, and S. A. Fuselier (1997), Relationships between plasma depletion and subsolar reconnection, J. Geophys. Res., 102(A5), 9531-9542, doi:10.1029/97JA00173.

Angelopoulos, V. (2008), The THEMIS mission, Space Sci. Rev., 141, 5-34, doi:10.1007/s11214-008-9336-1.

Auster, H. U., et al. (2008), The THEMIS fluxgate magnetometer, Space Sci. Rev., 141, 235-264, doi:10.1007/s11214-008-9365-9.

Bogdanova, Y. V., A. Marchaudon, C. J. Owen, M. W. Dunlop, H. U. Frey, J. A. Wild, A. N. Fazakerley, B. Klecker, J. A. Davies, and S. E. Milan (2005), On the formation of the high-altitude stagnant cusp: Cluster observations, Geophys. Res. Lett., 32, L12101, doi:10.1029/2005GL022813.

Bogdanova, Y. V., et al. (2008), Formation of the low-latitude boundary layer and cusp under the northward IMF: Simultaneous observations by Cluster and Double Star, J. Geophys. Res., 113, A07S07, doi:10.1029/ 2007JA012762.

Bonnell, J. W., et al. (2008), The electric field instrument (EFI) for THEMIS, Space Sci. Rev., 141, 303-341, doi:10.1007/s11214-008-9469-2. 
Cowley, S. W. H. (1983), Interpretation of observed relations between solar wind characteristics and effects at ionospheric altitudes, in High-Latitude Plasma Physics, edited by B. Hultqvist and T. Hagfors, pp. 225-249, Plenum, New York, doi:10.1007/978-1-4613-3652-5 13.

Crooker, N. U., T. E. Eastman, and G. S. Stiles (1979), Observations of plasma depletion in the magnetosheath at the dayside magnetopause, J. Geophys. Res., 84(A3), 869-874, doi:10.1029/JA084iA03p00869.

Cully, C. M., R. E. Ergun, K. Stevens, A. Nammari, and J. Westfall (2008), The THEMIS Digital Fields Board, Space Sci. Rev., 141(1-4), 343-355, doi:10.1007/s11214-008-9417-1.

Dunlop, M. W., et al. (2008), Electron structure of the magnetopause boundary layer: Cluster/Double Star observations, J. Geophys. Res., 113, A07S19, doi:10.1029/2007JA012788.

Dunlop, M. W., et al. (2011), Magnetopause reconnection across wide local time, Ann. Geophys., 29(9), 1683-1697, doi:10.5194/angeo-29-16832011.

Eastman, T. E., and E. W. Hones Jr. (1979), Characteristics of the magnetospheric boundary layer and magnetopause layer as observed by IMP 6, J. Geophys. Res., 84, 2019-2028, doi:10.1029/JA084iA05p02019.

Eastwood, J. P., M. A. Shay, T. D. Phan, and M. Øieroset (2010), Asymmetry of the ion diffusion region Hall electric and magnetic fields during guide field reconnection: Observations and comparison with simulations, Phys. Rev. Lett., 104(20), 205001, doi:10.1103/PhysRevLett.104.205001.

Egedal, J., A. Lê, N. Katz, L.-J. Chen, B. Lefebvre, W. Daughton, and A. Fazakerley (2010), Cluster observations of bidirectional beams caused by electron trapping during antiparallel reconnection, J. Geophys. Res., 115, A03214, doi:10.1029/2009JA014650.

Fuselier, S. A., B. J. Anderson, and T. G. Onsager (1995), Particle signatures of magnetic topology at the magnetopause: AMPTE/CCE observations, J. Geophys. Res., 100(A7), 11,805-11,821, doi:10.1029/ 94JA02811.

Fuselier, S. A., B. J. Anderson, and T. G. Onsager (1997), Electron and ion signatures of field line topology at the low-shear magnetopause, J. Geophys. Res., 102, 4847-4863, doi:10.1029/96JA03635.

Fuselier, S. A., M. Lockwood, T. G. Onsager, and W. K. Peterson (1999), The source population for the cusp and cleft/LLBL for southward IMF, Geophys. Res. Lett., 26, 1665-1669, doi:10.1029/1999GL900354.

Gosling, J. T., M. F. Thomsen, S. J. Bame, R. C. Elphic, and C. T. Russell (1990), Plasma flow reversals at the dayside magnetopause and the origin of asymmetric polar cap convection, J. Geophys. Res., 95(A6), 80738084, doi:10.1029/JA095iA06p08073.

Gosling, J. T., M. F. Thomsen, S. J. Bame, R. C. Elphic, and C. T. Russell (1991), Observations of reconnection of interplanetary and lobe magnetic field lines at high-latitude magnetopause, J. Geophys. Res., 96, 14,09714,106, doi:10.1029/91JA01139.

Hall, D. S., C. P. Chaloner, D. A. Bryant, D. A. Lepine, and V. P. Tritakis (1991), Electrons in the boundary layers near the dayside magnetopause, J. Geophys. Res., 96, 7869-7891, doi:10.1029/90JA02137.

Hapgood, M. A., and D. A. Bryant (1990), Re-ordered electron data in the low-latitude boundary layer, Geophys. Res. Lett., 17(11), 2043-2046, doi:10.1029/GL017i011p02043.

Heyn, M. F., H. K. Biernat, R. P. Rijnbeek, and V. S. Semenov (1988), The structure of reconnection layers, J. Plasma Phys., 40(2), 235-252, doi:10.1017/S0022377800013246.

Hu, R., Y. V. Bogdanova, C. J. Owen, C. Foullon, A. N. Fazakerley, and H. Rème (2008), Cluster observations of the midaltitude cusp under strong northward interplanetary magnetic field, J. Geophys. Res., 113, A07S05, doi:10.1029/2007JA012726.

Huang, C., Q. Lu, and S. Wang (2010), The mechanisms of electron acceleration in antiparallel and guide field magnetic reconnection, Phys. Plasmas, 17(7), 072306, doi:10.1063/1.3457930.

Kessel, R. L., S.-H. Chen, J. L. Green, S. F. Fung, S. A. Boardsen, L. C. Tan, T. E. Eastman, J. D. Craven, and L. A. Frank (1996), Evidence of high-latitude reconnection during northward IMF: Hawkeye observations, Geophys. Res. Lett., 23, 583-586, doi:10.1029/95GL03083.

Khotyaintsev, Y. V., A. Vaivads, A. Retinò, M. André, C. J. Owen, and H. Nilsson (2006), Formation of inner structure of a reconnection separatrix region, Phys. Rev. Lett., 97(20), 205003, doi:10.1103/ PhysRevLett.97.205003.

Lavraud, B., et al. (2002), Cluster observations of the exterior cusp and its surrounding boundaries under northward IMF, Geophys. Res. Lett., 29(20), 1995, doi:10.1029/2002GL015464.

Lavraud, B., M. F. Thomsen, M. G. G. T. Taylor, Y. L. Wang, T. D. Phan, S. J. Schwartz, R. C. Elphic, A. Fazakerley, H. Rème, and A. Balogh (2005), Characteristics of the magnetosheath electron boundary layer under northward interplanetary magnetic field: Implications for high-latitude reconnection, J. Geophys. Res., 110, A06209, doi:10.1029/ 2004JA010808.
Lavraud, B., M. F. Thomsen, B. Lefebvre, S. J. Schwartz, K. Seki, T. D. Phan, Y. L. Wang, A. Fazakerley, H. Rème, and A. Balogh (2006), Evidence for newly closed magnetosheath field lines at the dayside magnetopause under northward IMF, J. Geophys. Res., 111, A05211, doi: $10.1029 / 2005$ JA011266.

Lockwood, M. (1997), The relationship of dayside auroral precipitations to the open-closed separatrix and the pattern of convective flow, J. Geophys. Res., 102, 17,475-17,487, doi:10.1029/97JA01100.

Lockwood, M., and M. A. Hapgood (1997), How the magnetopause transition parameter works, Geophys. Res. Lett., 24(4), 373-376, doi:10.1029/ 97GL00120.

Lockwood, M., and M. A. Hapgood (1998), On the cause of a magnetospheric flux transfer event, J. Geophys. Res., 103, 26,453-26,478, doi:10.1029/98JA02244.

Lockwood, M., and J. Moen (1996), Ion populations on open field lines within the low-latitude boundary layer: Theory and observations during a dayside transient event, Geophys. Res. Lett., 23, 2895-2898, doi:10.1029/96GL02761.

Lockwood, M., and J. Moen (1999), Reconfiguration and closure of lobe flux by reconnection during northward IMF: Possible evidence for signatures in cusp/cleft auroral emissions, Ann. Geophys., 17, 996-1011, doi:10.1007/s00585-999-0996-2.

Lockwood, M., S. W. H. Cowley, M. F. Smith, R. P. Rijnbeek, and R. C Elphic (1995), The contribution of flux transfer events to convection, Geophys. Res. Lett., 22, 1185-1188, doi:10.1029/95GL01008.

Lockwood, M., et al. (2001), Coordinated Cluster and ground-based instrument observations of transient changes in the magnetopause boundary layer during an interval of predominantly northward IMF: Relation to reconnection pulses and FTE signatures, Ann. Geophys., 19(10/12), 1613-1640, doi:10.5194/angeo-19-1613-2001.

McComas, D. J., S. J. Bame, P. Barker, W. C. Feldman, J. L. Phillips, P. Riley, and J. W. Griffee (1998), Solar Wind Electron Proton Alpha Monitor (SWEPAM) for the Advanced Composition Explorer, Space Sci. Rev., 86, 563-612, doi:10.1023/A:1005040232597.

McFadden, J. P., C. W. Carlson, D. Larson, V. Angelopoulos, M. Ludlam, R. Abiad, B. Elliott, P. Turin, and M. Marckwordt (2008), The THEMIS ESA plasma instrument and in-flight calibration, Space Sci. Rev., 141 277-302, doi:10.1007/s11214-008-9440-2.

Mitchell, D. G., F. Kutchko, D. J. Williams, T. E. Eastman, L. A. Frank, and C. T. Russell (1987), An extended study of the low-latitude boundary layer on the dawn and dusk flank of the magnetosphere, J. Geophys. Res., 92, 7394-7404, doi:10.1029/JA092iA07p07394.

Nakamura, M., and M. Scholer (2000), Structure of the magnetopause reconnection layer and of flux transfer events: Ion kinetic effects, J. Geophys. Res., 105(A10), 23,179-23,191, doi:10.1029/2000JA900101.

Øieroset, M., D. L. Mitchell, T. D. Phan, R. P. Lin, D. H. Crider, and M. H. Acuna (2004), The magnetic field pile-up and density depletion in the Martian magnetosheath: A comparison with the plasma depletion layer upstream of the Earth's magnetopause, Space Sci. Rev., 111(1-2), 185-202, doi:10.1023/B:SPAC.0000032715.69695.9c

Onsager, T. G., J. D. Scudder, M. Lockwood, and C. T. Russell (2001), Reconnection at the high-latitude magnetopause during northward interplanetary magnetic field conditions, J. Geophys. Res., 106, 25,467-25,488, doi:10.1029/2000JA000444

Paschmann, G. (2008), Recent in-situ observations of magnetic reconnection in near-Earth space, Geophys. Res. Lett., 35, L19109, doi:10.1029/ 2008GL035297.

Paschmann, G., W. Baumjohann, N. Sckopke, T. D. Phan, and H. Luehr (1993), Structure of the dayside magnetopause for low magnetic shear, J. Geophys. Res., 98(A8), 13,409-13,422, doi:10.1029/93JA00646.

Phan, T.-D., M. Oieroset, and M. Fujimoto (2005), Reconnection at the dayside low-latitude magnetopause and its nonrole in low-latitude boundary layer formation during northward interplanetary magnetic field, Geophys. Res. Lett., 32, L17101, doi:10.1029/2005GL023355.

Pritchett, P. L., and F. S. Mozer (2009), Asymmetric magnetic reconnection in the presence of a guide field, J. Geophys. Res., 114, A11210, doi:10.1029/2009JA014343.

$\mathrm{Pu}, \mathrm{Z}$. Y., et al. (2007), Global view of dayside magnetic reconnection with the dusk-dawn IMF orientation: A statistical study for Double Star and Cluster data, Geophys. Res. Lett., 34, L20101, doi:10.1029/ 2007GL030336.

Retinò, A., et al. (2005), Cluster multispacecraft observations at the highlatitude duskside magnetopause: Implications for continuous and component magnetic reconnection, Ann. Geophys., 23, 461-473, doi:10.5194/ angeo-23-461-2005.

Retinò, A., et al. (2006), Structure of the separatrix region close to a magnetic reconnection X-line: Cluster observations, Geophys. Res. Lett., 33 , L06101, doi:10.1029/2005GL024650. 
Roux, A., et al. (2008), The search coil magnetometer for THEMIS, Space Sci. Rev., 141, 265-275, doi:10.1007/s11214-008-9455-8.

Scurry, L., C. T. Russell, and J. T. Gosling (1994), A statistical study of accelerated flow events at the dayside magnetopause, J. Geophys. Res., 99(A8), 14,815-14,829, doi:10.1029/94JA00793.

Sibeck, D. G., and V. Angelopoulos (2008), THEMIS science objectives and mission phases, Space Sci. Rev., 141, 35-59, doi:10.1007/s11214 008-9393-5.

Smith, C. W., M. H. Acuna, L. F. Burlaga, J. L'Heureux, N. F. Ness, and J. Scheifele (1998), The ACE Magnetic Fields Experiment, Space Sci. Rev., 86, 613-632, doi:10.1023/A:1005092216668.

Song, P., and C. T. Russell (1992), Model of the formation of the lowlatitude boundary layer for strongly northward interplanetary magnetic field, J. Geophys. Res., 97(A2), 1411-1420, doi:10.1029/91JA02377.

Trattner, K. J., J. S. Mulcock, S. M. Petrinec, and S. A. Fuselier (2007), Probing the boundary between antiparallel and component reconnection during southward interplanetary magnetic field conditions, J. Geophys. Res., 112, A08210, doi:10.1029/2007JA012270.

Vaivads, A., Y. Khotyaintsev, M. André, A. Retinò, S. C. Buchert, B. N. Rogers, P. Décréau, G. Paschmann, and T. D. Phan (2004), Structure of the magnetic reconnection diffusion region from four-spacecraft observations, Phys. Rev. Lett., 93(10), 105001, doi:10.1103/PhysRevLett.93.105001.

Vaivads, A., A. Retinò, Y. V. Khotyaintsev, and M. André (2010), The Alfvén edge in asymmetric reconnection, Ann. Geophys., 28(6), 1327-1331, doi:10.5194/angeo-28-1327-2010.

Wang, R., Q. Lu, A. Du, and S. Wang (2010a), In situ observations of a secondary magnetic island in an ion diffusion region and associated energetic electrons, Phys. Rev. Lett., 104, 175003, doi:10.1103/ PhysRevLett.104.175003.

Wang, R., Q. Lu, C. Huang, and S. Wang (2010b), Multispacecraft observation of electron pitch angle distributions in magnetotail reconnection, J. Geophys. Res., 115, A01209, doi:10.1029/2009JA014553.

Zhang, Q.-H., R. Y. Liu, M. W. Dunlop, J. Y. Huang, H. Q. Hu, M. Lester, Y. H. Liu, Z. J. Hu, Q. Q. Shi, and M. G. G. T. Taylor (2008), Simultaneous tracking of reconnected flux tubes: Cluster and conjugate SuperDARN observations on 1 April 2004, Ann. Geophys., 26, 1545-1557, doi:10.5194/angeo-26-1545-2008

Zhang, Q.-H., et al. (2010), Simultaneous observations of reconnection pulses at Cluster and their effects on the cusp aurora observed at the Chinese Yellow River Station, J. Geophys. Res., 115, A10237, doi:10.1029/2010JA015526. 